\title{
Molecular and Morphological Redescriptions of Enteric Myxozoans, Enteromyxum leei (formerly Myxidium sp. TP) and Enteromyxum fugu comb. n. (syn. Myxidium fugu) from Cultured Tiger Puffer
}

\author{
Tetsuya Yanagida ${ }^{1}$, Yoshinori Nomura ${ }^{2}$, Takeshi Kimura², Yutaka Fukuda ${ }^{3}$, \\ Hiroshi Yokoyama $^{1 *}$ and Kazuo Ogawa ${ }^{1}$ \\ ${ }^{1}$ Department of Aquatic Bioscience, Graduate School of Agricultural and Life Sciences, \\ The University of Tokyo, Tokyo 113-8657, Japan \\ ${ }^{2}$ Kumamoto Prefectural Fisheries Research Center, Amakusa, \\ Kumamoto 869-3603, Japan \\ ${ }^{3}$ Oita Institute of Marine and Fisheries Science, Kamiura, \\ Oita 879-2602, Japan
}

(Received March 19, 2004)

\begin{abstract}
The phylogenies of two enteric myxozoans, Myxidium fugu and Myxidium sp. TP, from cultured tiger puffer Takifugu rubripes were re-evaluated based on their small subunit ribosomal RNA (SSU rRNA) gene sequence and spore morphology. Phylogenetic analysis shows that M. fugu and Myxidium sp. TP are grouped with Enteromyxum species as a monophyletic clade, not with other Myxidium spp. It was also illustrated that spores of $M$. fugu satisfy the criteria for the genus Enteromyxum for spore morphology. SSU rRNA gene sequence of Myxidium sp. TP shared $99.6 \%$ identity to that of Enteromyxum leei. Experimental transmission of Myxidium sp. TP to red sea bream Pagrus major induced the formation of mature spores, which were indistinguishable from those of $E$. leei in morphology and morphometrics. Myxidium sp. TP is identified as E. leei, and M. fugu is reassigned as Enteromyxum fugu comb. n.
\end{abstract}

Key words: Enteromyxum, Enteromyxum leei, Myxidium, SSU rRNA, Takifugu rubripes, emaciation disease, Pagrus major

The emaciation disease has emerged since the mid 1990s in the Japanese culture fields of tiger puffer Takifugu rubripes. Affected fish showed clinical signs of severe emaciation including sunken eyes, bony ridges on the head and a tapered body (Ogawa and Yokoyama, 2001). In the intestine of the infected fish, two new myxozoans, Myxidium fugu and Leptotheca fugu, and one unidentified myxozoan tentatively designated as Myxidium sp. TP (Tin Tun et al., 2000) were found. Histopathological studies indicated that Myxidium sp. TP and $L$. fugu, histozoic parasites of the intestinal epithelium, were highly pathogenic and responsible for the emaciation disease (Ogawa and Yokoyama, 2001; Tin Tun et al., 2002).

Myxidium sp. TP was first placed in the genus

\footnotetext{
* Corresponding author

E-mail: ayokoh@mail.ecc.u-tokyo.ac.jp
}

Myxidium according to the morphology of immature spores (Tin Tun et al., 2000) but has not been identified to the species level so far because of the absence of mature spore formation. It is unknown why Myxidium $\mathrm{sp}$. TP could not fully mature to the spore stage. We speculate that tiger puffer may be an "abnormal host" for this parasite. Myxidium sp. TP appears to be closely related to the myxozoans belonging to the genus Enteromyxum, due to their marine, histozoic and enteric characteristics. Enteromyxum leei is pathogenic and infects the intestine of mainly sparid fishes including gilthead sea bream Sparus aurata and red sea bream Pagrus major, in which the parasite forms numerous spores (Diamant, 1997). This parasite was first described as Myxidium leei (Diamant et al., 1994) but Palenzuela et al. (2002) recognized that $M$. leei did not properly fit into the genus Myxidium according to the morphological and molecular analyses, and conse- 
quently transferred $M$. leei to the genus Enteromyxum.

In the present study, we conducted the SSU rRNA gene sequence analysis of $M$. fugu and Myxidium sp. TP to re-evaluated their taxonomic positions. Additionally, a transmission experiment to red sea bream was attempted to produce mature spores of Myxidium sp. TP for the morphological examination of this parasite.

\section{Materials and Methods}

Molecular analysis

Parasites: The enteric myxozoans were obtained from the intestinal tissues of heavily infected tiger puffer, and then preserved in $80 \%$ ethanol. The sample of $M$. fugu was collected from cage-cultured tiger puffer located in Kumamoto Prefecture, while Myxidium sp. TP was provided from a tiger puffer farmer in Oita Prefecture. Previous examinations showed that the fish from Kumamoto was infected only with $M$. fugu, whereas the fish from Oita was infected with both $M$. fugu and Myxidium sp. TP.

DNA cloning and sequencing: Parasite DNA was extracted from the suspension of scraped intestinal mucosa, using QIAamp DNA Mini Kit (Qiagen Inc., Germany). Myxozoan nuclear SSU rDNA was amplified by PCR using the primers MM18Sf (ctggttgattctgccagtggtc) and MM18Sr (cggtactagcgacgggcg) which have been used for the amplification of SSU rDNA of some marine enteric myxozoans (Palenzuela et al., 2002). For $M$. fugu, the products were ligated into a vector (pT7Blue T-Vector, Novagen, USA), which was used to transform competent Escherichia coli cells (JM109, TaKaRa, Japan). On the other hand, the PCR Cloning $^{+}$Kit (Qiagen) was used for the PCR products from the template containing both $M$. fugu and Myxidium sp. TP DNA. Transformants were selected by the blue/ white screening method on plates containing $X-G a l$ and the presence of the inserts of the expected size was confirmed by PCR using commercial primers which amplify the insert regions. Both strands of the DNA were sequenced from at least 3 different clones containing each myxozoan gene, using an ABI PRISM 310 sequencer (Applied Biosystems, USA). Because of the coinfection of two myxozoans, SSU rRNA gene sequence of $M$. fugu was firstly determined and then clones containing a gene different from $M$. fugu were used for Myxidium sp. TP. Consensus sequence assemblages were aided with Genetyx Mac 10.0 and Genetyx Mac ATSQ 3.0 (Software Development, Japan).

Phylogenetic inference: Sequences were aligned using Genetyx Mac 10.0 and ClustalX1.8 (Thompson et al., 1997) with the homologous sequences from other myxozoans available on public databases. Unambiguously aligned positions were used for phylogenetic inferrence performed by PAUP v.4.0b4 (Swofford, 1999) using the neighbor-joining (NJ) method applied to dis- tances corrected according to Kimura's 2-parameter model (Kimura, 1980). Missing-data sites, including gaps, were ignored. Support for the internal branches of the tree was assessed by 100 bootstrap resamplings of the data set (Felsenstein, 1985). PKX organism (U70623) was selected as an outgroup, as it is a member of the Malacosporea, another class in the phylum Myxozoa, which has been demonstrated to be an outlier from other myxosporeans according to the analysis of SSU rRNA gene sequences (Kent and Palenzuela, 2002). GenBank accession numbers of additional sequences utilized in this analysis are shown in Fig. 1.

\section{Experimental transmission to red sea bream}

Fish: A stock of tiger puffer coinfected with $M$. fugu and Myxidium sp. TP was kept as the donor fish for the experimental infection in the facilities of Kumamoto Prefectural Fisheries Research Center. The infection cycle was maintained in vivo by cohabitation of the infected donor fish and uninfected tiger puffer until required. Specific-myxozoan-free red sea bream were provided from a commercial hatchery in Kumamoto Prefecture and held in aquaria using filtered seawater in the Research Center.

Transmission experiment by feeding: From 10 infected donor tiger puffer described above, the intestines were freshly collected and chopped. A group of 21 naïve red sea bream (average body weight, $140 \mathrm{~g}$ ) was fed pieces of the gut tissues. Subsequently, the fish were placed in a $500 \mathrm{~L}$ tank supplied with flowthrough-filtrated seawater maintained at $25^{\circ} \mathrm{C}$. At time intervals of 3,6 and 9 weeks post-feeding, 7 fish were randomly selected from the tank and examined for Myxidium infections as described below. Twenty-one control fish were held in another tank under equivalent conditions and examined for the parasites.

Parasitological examination: Following the dissection of test fish, the digestive tracts were opened and gut contents were removed by washing with filtered seawater. Imprint slides of the intestinal mucosa were prepared for each individual fish, air-dried and stained with Diff-Quik (International Reagents Corp., Japan) for microscopical observation. Pieces of the gut tissues were fixed in $10 \%$ formalin and processed by routine histology. Paraffin sections cut at $5 \mu \mathrm{m}$ were stained with Uvitex 2B (Ciba Geigy, Switzerland) and hematoxylin-eosin and observed under a light microscope (Yokoyama et al., 1996). For comparison, the intestinal tissue sections of sharpsnout sea bream Diplodus puntazzo infected with Enteromyxum leei and of turbot Scophthalmus maximus infected with Enteromyxum scophthalmi were prepared for Uvitex 2B-stainability. For spore morphology, the frozen intestines of tiger puffer and red sea bream were thawed and scrapings of the intestinal mucosa were suspended in phosphate buffered saline. Drops of the suspensions were placed 
on the glass slides, and the spore morphology was examined in wet mounts under a phase-contrast microscope. Digital spore images were taken and measurements were made for 20 spores from the multiple images.

\section{Results}

\section{Analysis of SSU rRNA gene sequence}

SSU rRNA gene sequences of 1,590 bp and 1,588 bp were obtained from $M$. fugu and Myxidium sp. TP, respectively. The sequence of Myxidium sp. TP shared a $99.6 \%$ identity to that of $E$. leei. A phylogenic tree constructed with $\mathrm{NJ}$ method revealed that $M$. fugu and Myxidium sp. TP grouped with Enteromyxum leei and Enteromyxum scophthalmi as a monophyletic clade, with maximum bootstrap support (Fig. 1). This clade was also distinct from that containing all the species from the genus Myxidium available on the database. The sequence data determined in the current study have been deposited in GenBank as follows: Enteromyxum fugu (syn. Myxidium fugu); accession number AY520573; Enteromyxum leei (= Myxidium sp. TP); AY520574.

\section{Experimental transmission to red sea bream}

The developmental stages of $M$. fugu and Myxidium sp. TP were first detected in the intestine of experimentally infected fish at 6 weeks post-feeding of infected materials (Table 1). Prevalence of infection with $M$. fugu reached $100 \%$ (7 infected fish out of 7 examined fish) by 6 weeks, while that of Myxidium sp. TP was $57 \%$ (4 out of 7) and 50\% (2 out of 4) by 6 and 9 weeks, respectively. At week 9, some mature spores of Myxidium sp. TP were observed in the intestine of red sea bream. No clinical signs of the emaciation disease were exhibited during the experimental period.

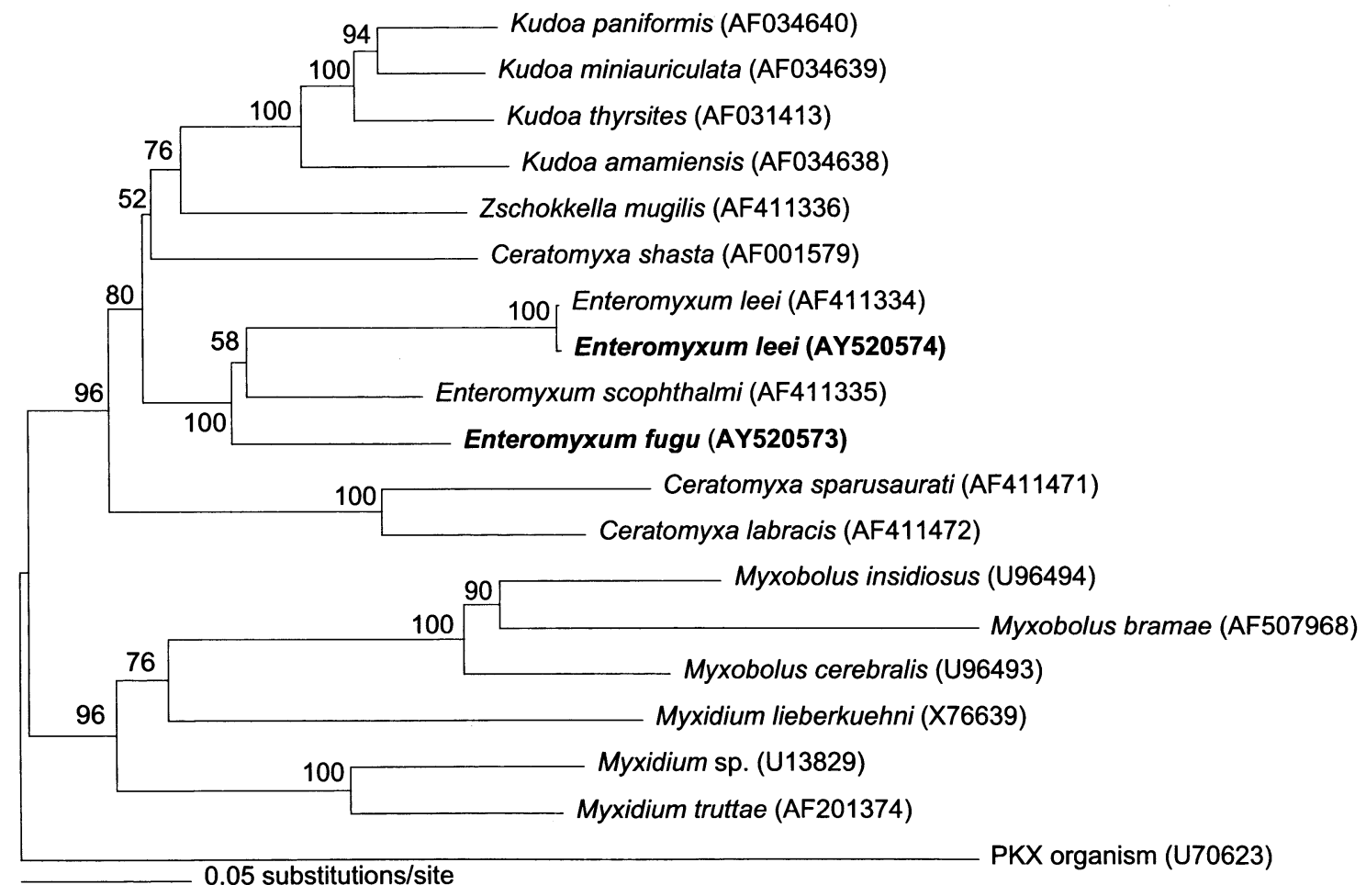

Fig. 1. Phylogenetic tree inferred from neighbor-joining analysis of the SSU rRNA gene from Enteromyxum leei (= Myxidium sp. TP), Enteromyxum fugu and related myxozoans. Bootstrap values obtained out of 1000 samplings are shown at nodes.

Table 1. Experimental transmission of Myxidium fugu and Myxidium sp. Tp to red sea bream by feeding infected gut tissue of tiger puffer

\begin{tabular}{cccccccc}
\hline \multirow{2}{*}{$\begin{array}{c}\text { Weeks post- } \\
\text { feeding }\end{array}$} & $\begin{array}{c}\text { Average body } \\
\text { weight }(\mathrm{g})\end{array}$ & M. fugu & Myxidium sp. TP & $\begin{array}{c}\text { Average body } \\
\text { weight }(\mathrm{g})\end{array}$ & M. fugu & Myxidium sp. TP \\
\hline 3 & 157 & $0 / 7^{*}$ & $0 / 7$ & & 144 & $0 / 7$ & $0 / 7$ \\
6 & 167 & $0 / 7$ & $0 / 7$ & & 200 & $7 / 7$ & $4 / 7$ \\
9 & 174 & $0 / 7$ & $0 / 7$ & & 131 & $6 / 7$ & $2 / 4$ \\
\hline
\end{tabular}

*: Number of infected fish / number of examined fish 


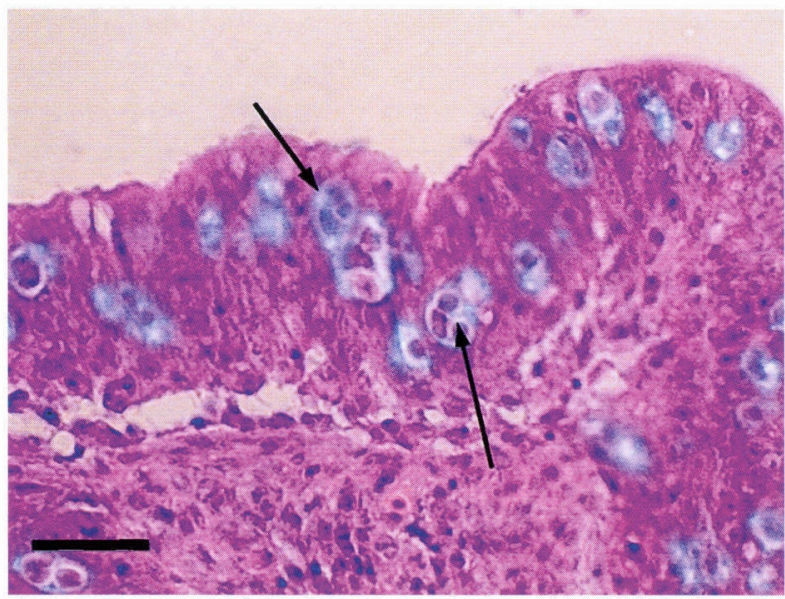

Fig. 2. Gut epithelium of red sea bream experimentally infected with Enteromyxum leei (arrows). Uvitex 2B-H \& E stains. Dual exposure with UV and normal light. $B a r=30 \mu \mathrm{m}$.
Histologically, it was shown that Myxidium sp. TP developed intercellulary in the gut epithelium and that the intestinal epithelial lining undulated in places (Fig. 2). Plasmodia of Myxidium sp. TP in red sea bream were found to be strongly stained by Uvitex $2 B$ (Fig. 2), as documented in the tiger puffer (Tin Tun et al., 2000). Enteromyxum leei in the sharpsnout sea bream also stained positive with Uvitex $2 \mathrm{~B}$, while E. scophthalmi was negative (data not shown).

\section{Spore morphology}

Spores of Myxidium sp. TP from the experimentally infected red sea bream were identical in shape to those of Enteromyxum leei. The spores were slightly crescent in shape and polar capsules were large, elongated, tapering distally and opening at the ends of the spore (Figs. 3a and b). Measurements of spores are
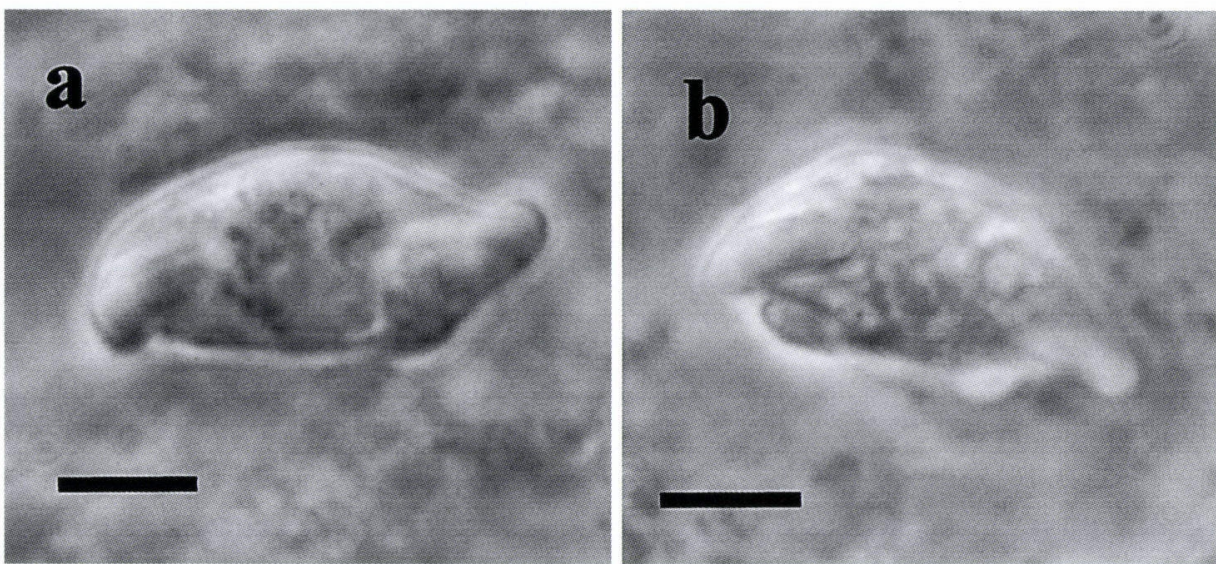

Fig. 3. Fresh spores of Enteromyxum leei (= Myxidium sp. TP) from red sea bream. Phase-contrast microscopy. a: top view. b: frontal view. Bars $=5 \mu \mathrm{m}$.

Table 2. Comparison of the spore dimensions (mean $\pm \mathrm{s}$. $\mathrm{d}$. and range in parentheses) between Enteromyxum leei and Myxidium sp. TP

\begin{tabular}{|c|c|c|c|c|c|}
\hline \multirow{2}{*}{$\begin{array}{r}\text { Myxozoan } \\
\text { Host }\end{array}$} & \multicolumn{2}{|c|}{ Spore $(\mu \mathrm{m})$} & \multicolumn{2}{|c|}{ Polar capsule $(\mu \mathrm{m})$} & \multirow{2}{*}{ Reference } \\
\hline & Length & Width & Length & Width & \\
\hline \multicolumn{6}{|l|}{ Enteromyxum leei } \\
\hline Sparus aurata & $\begin{array}{c}14.7 \\
(13.2-15.2)\end{array}$ & $\begin{array}{c}6.9 \\
(5.6-7.8)\end{array}$ & $\begin{array}{c}74 \\
(6.2-8.8)\end{array}$ & $\begin{array}{c}3.2 \\
(2.8-3.8)\end{array}$ & $\begin{array}{l}\text { Diamant et al. } \\
\quad(1994)^{*}\end{array}$ \\
\hline Sparus aurata & $15-18$ & $7-8$ & 7 & 3 & Diamant (1992)* \\
\hline Sparus aurata & $\begin{array}{c}16.7 \pm 1 \\
(15-18)\end{array}$ & $\begin{array}{c}9.7 \pm 1 \\
(8-11)\end{array}$ & $\begin{array}{l}8.5 \pm 1.3 \\
(8-9)\end{array}$ & $\begin{array}{l}2.7 \pm 0.7 \\
(2.5-4)\end{array}$ & Sakiti et al. (1996) \\
\hline Sparus aurata & $\begin{array}{c}17.7 \pm 0.6 \\
(16.7-18.4)\end{array}$ & $\begin{array}{c}8.2 \pm 0.4 \\
(7.5-8.1)\end{array}$ & $\begin{array}{c}7.7 \pm 0.3 \\
(7.5-8.1)\end{array}$ & $\begin{array}{c}2.9 \pm 0.4 \\
(2.3-3.5)\end{array}$ & $\begin{array}{l}\text { Padros et al. } \\
(2001)^{* *}\end{array}$ \\
\hline Sparus aurata & $\begin{array}{c}16.2 \\
(15.2-17.7)\end{array}$ & $\begin{array}{c}7.8 \\
(7.5-8.6)\end{array}$ & $\begin{array}{c}8.2 \\
(6.9-9.8)\end{array}$ & $\begin{array}{c}3.6 \\
(3.1-4.3)\end{array}$ & Diamant (1998) \\
\hline $\begin{array}{c}\text { Diplodus pundazzo } \\
\text { \& Pagrus major }\end{array}$ & $15-19$ & $5-7$ & $6.5-9$ & $2.5-4$ & $\begin{array}{c}\text { Le Breton \& } \\
\text { Marques (1995) }\end{array}$ \\
\hline \multicolumn{6}{|l|}{ Myxidium sp. TP } \\
\hline Pagrus major & $\begin{array}{c}17.5 \pm 0.9 \\
(15.9-19.1)\end{array}$ & $\begin{array}{c}9.2 \pm 2.4 \\
(7.9-11.0)\end{array}$ & $\begin{array}{c}6.4 \pm 0.4 \\
(6.1-7.2)\end{array}$ & $\begin{array}{c}3.0 \pm 0.6 \\
(2.1-3.6)\end{array}$ & This study \\
\hline
\end{tabular}

\footnotetext{
* Materials fixed in formalin

*** Material fixed in ethanol and re-hydrated in HBSS
} 
given in Table 2. Polar filaments and sutural line were not clearly visible.

The spore morphology of Myxidium fugu from tiger puffer satisfied the criteria for the genus Enteromyxum previously described by Palenzuela et al. (2002), i.e., slightly crescent shaped, large and elongated polar capsules tapering to their distal side and opening at the end
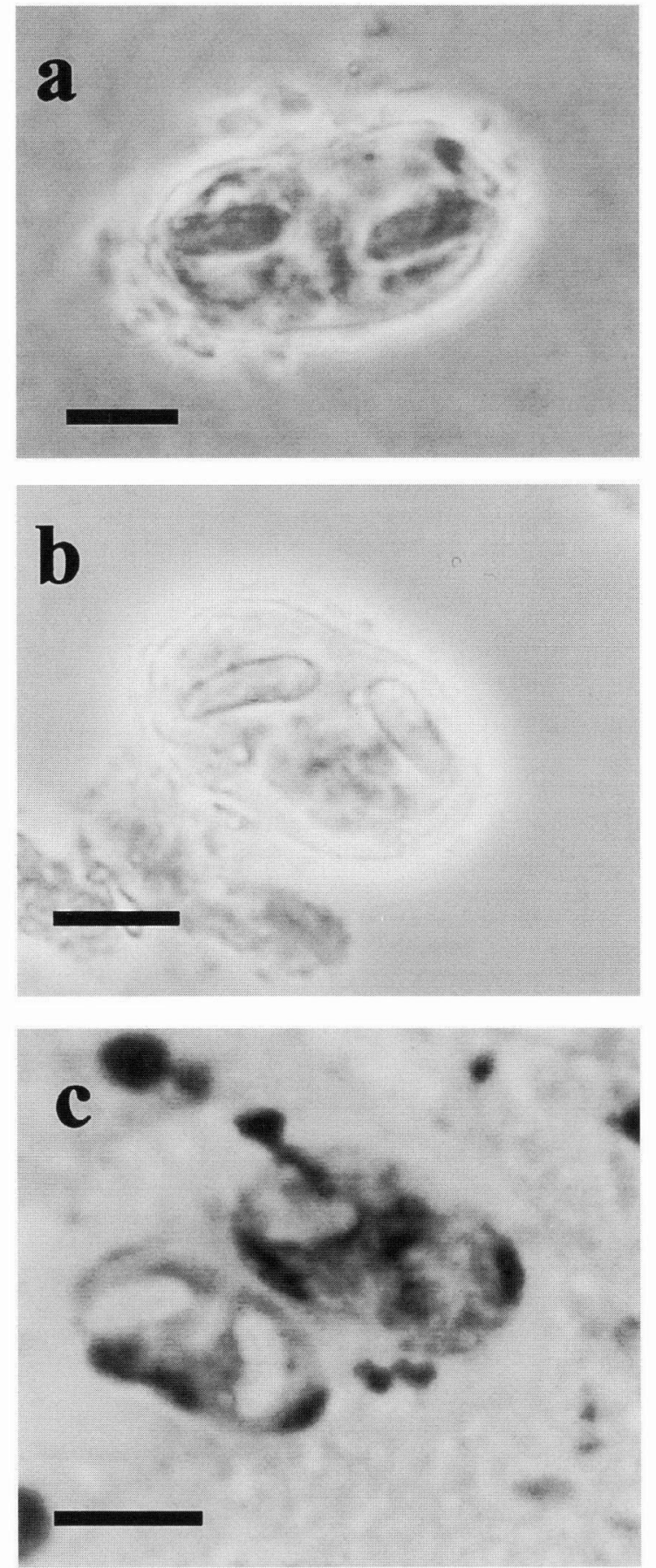

Fig. 4. Enteromyxum fugu. a, b: fresh spores on top (a) and front (b) views. Bars $=5 \mu \mathrm{m}$. Phase-contrast microscopy. c: intestinal imprint stained with Diff-Quik. A disporous plasmodium is observed. Bar $=10 \mu \mathrm{m}$. of the spore, but discharging in opposite directions relative to a longitudinal plane bisecting the spore in top or bottom view (Figs. $4 \mathrm{a}$ and $4 \mathrm{~b}$ ). It was also illustrated that spores developed in disporic sporoblasts (Fig. $4 c)$.

\section{Discussion}

SSU rRNA gene analysis in this study strongly suggests that Myxidium sp. TP and E. leei are the same species. Molecular data alone is considered inadequate to identify myxozoan species but has been widely utilized to support the validity of morphological evidence. Yokoyama et al. (2004a) demonstrated that SSU rRNA gene sequences shared $100 \%$ identity between Myxobolus buri from yellowtail Seriola quinqueradiata and Myxobolus acanthogobii from yellowfin goby Acanthogobius flavimanus, concluding the synonymy of the 2 parasites. In contrast, Schlegel et al. (1996) documented a $2 \%$ variation within Myxidium lieberkuehni SSU rRNA gene sequences that were derived from various isolates of the same species. Yokoyama et al. (2004b) also found a difference of $0.9 \%$ between Japanese and Canadian isolates of Kudoa thyrsites. It is highly likely that the minor difference $(0.4 \%)$ in the present study between the SSU rRNA sequences of Myxidium sp. TP and E. leei is within intraspecific variation.

An experimental transmission of Myxidium sp. TP to red sea bream, for the first time, induced the formation of mature spores, allowing us to observe the spore morphology of this parasite. Morphological comparison between spores of Myxidium sp. TP from red sea bream and those of $E$. leei from different references also supports the two myxozoans being the same organism. The spore morphometry of Myxidium sp. TP was consistent with that of $E$. leei and distinct from the only other current member of the genus, E. scophthalmi, which is considerably larger than E. leei. Although minor morphometric differences were detected between Myxidium $\mathrm{sp}$. TP and various isolates of $E$. leei, the variability might be caused by different preparations. It is possible that somewhat small sizes of spore dimensions given by Diamant (1992) and Diamant et al. (1994) are due to shrinkage of spores fixed in formalin, whereas the measurements in the present study were taken from thawed spores. Otherwise, it may be explained by the host difference, which could possibly affect the final size of myxozoan spores. Diamant (1998) proved that experimental transmission of $E$. leei between gilt-head sea bream and red drum Sciaenops ocellatus produced different sizes of the spores.

One of the most unique characters of Enteromyxum species is fish-to-fish transmission of the parasites (Diamant, 1997; Redondo et al., 2002). Myxidium sp. TP and Myxidium fugu were also demonstrated to trans- 
mit directly from fish to fish (Yasuda et al., 2002). In the present study, experimental infection of Myxidium spp. from tiger puffer to red sea bream was achieved, suggesting that the direct transmission is a common biological feature for Enteromyxum spp., as well as the broad host range (Padros et al., 2001). Positive stainability of E. leei for Uvitex 2B indicates that developmental stages of the parasite possess a chitin component, which was also reported for Myxidium sp. TP (Tin Tun et al., 2000). Potential roles and functions of chitin in the parasites remain unknown, but Uvitex $2 B$ stainability may become complementary criteria for a diagnostic feature for E. leei.

Molecular and morphological evidence of $M$. fugu revealed the close affinity with the genus Enteromyxum. One inconsistency is that $M$. fugu is a coelozoic parasite, while all the other species of Enteromyxum are histozoic. However, this genus was established very recently and only two species ( $E$. leei and $E$. scophthalmi) have been included so far. Thus, we now propose to change the diagnosis of the Enteromyxum to accommodate a coelozoic parasite in the digestive system of marine fish and to transfer $M$. fugu to Enteromyxum fugu comb. $\mathrm{n}$.

It has recently been of great concern that exotic pathogens may be translocated by the importation of culture seedlings (Wakabayashi, 1996). Chronologically, Diamant (1992) documented that the first outbreak of $E$. leei was in 1991-1992 in Cyprus, followed by expansion into Mediterranean countries, whereas in Japan, the emaciation disease of tiger puffer was first noticed in 1996. This time lag implies that the origin of this parasite is from European countries, though we have no convincing evidence of the introduction of fish seedlings harboring the parasite. Alternatively, a report by Kent (1999) may give us another view for the origin. He found a myxozoan resembling $E$. leei from the anemone fish Amphiprion frenatus reared in the aquarium in San Diego, California, whose brood stock was captured from the Indo-Pacific Ocean. Although this parasite has not yet been identified, $E$. leei may be originally a parasite of tropical fishes that have been transferred to Japan in aquarium fish. To solve these questions, further molecular studies using a more variable region of the gene (the ITS region) derived from wide geographical and different host samples are required (Andree et al., 1999).

In conclusion, we reexamined the 2 enteric myxozoans from cultured tiger puffer based on the molecular and morphological studies, and identified Myxidium sp. TP as Enteromyxum leei and reassigned M. fugu as Enteromyxum fugu comb. $\mathrm{n}$.

\section{Acknowledgements}

We are thankful to Dr. Oswaldo Palenzuela, Instituto de Acuicultura de Torre la Sal, for kindly sending paraffin embedded samples of Enteromyxum leei-infected and Enteromyxum scophthalmi-infected tissues and to Dr. Mark A. Freeman, the University of Tokyo, for reviewing this manuscript.

\section{References}

Andree, K. B., M. El-Matbouli, R. W. Hoffman and R. P. Hedrick (1999): Comparison of $18 S$ and ITS-1 sequences of selected geographic isolates of Myxobolus cerebralis. Int. J. Parasitol., 29, 771-775.

Diamant, A. (1992): A new pathogenic histozoic Myxidium (Myxosporea) in cultured gilt-head sea bream Sparus aurata L. Bull. Eur. Ass. Fish Pathol., 12, 64-66.

Diamant, A. (1997): Fish-to-fish transmission of a marine myxosporean. Dis. Aquat. Org., 30, 99-105.

Diamant, A. (1998): Red drum Sciaenops ocellatus (Sciaenidae), a recent introduction to Mediterranean mariculture, is susceptible to Myxidium leei (Myxosporea). Aquaculture, 162, 33-39.

Diamant, A., J. Lom and I. Dyková (1994): Myxidium leei n. sp., a pathogenic myxosporean of cultured sea bream Sparus aurata. Dis. Aquat. Org., 20, 137-141.

Felsenstein, J. (1985): Confidence limits on phylogenies: an approach using the bootstrap. Evolution, 39, 783-791.

Kent, M. (1999): A myxozoan resembling Myxidium leei in the anemone fish Amphiprion frenatus from the Pacific Ocean. Bull. Eur. Ass. Fish Pathol., 19, 42-43.

Kent, M. L. and O. Palenzuela (2002): Myxozoa. In "Encyclopedia of life sciences", Nature Publishing Group, London, 12, pp. 612-618.

Kimura, M. (1980): A simple method for estimating evolutionary rates of base substitutions through comparative studies of nucleotide sequences. J. Molecular Evolution, 16, 111120.

Le Breton, A. and A. Marques (1995): Occurrence of a histozoic Myxidium infection in two marine cultured species: Puntazzo puntazzo C. and Pagrus major. Bull. Eur. Ass. Fish Pathol., 15, 210-212.

Ogawa, K. and H. Yokoyama (2001): Emaciation disease of cultured tiger puffer Takifugu rubripes. Bull. Natl. Res. Inst. Aquacult., Suppl., 5, 65-70.

Padrós, F., O. Palenzuela, C. Hispano, O. Tosas, C. Zaraza, S. Crespo and P. Álvarez-Pellitero (2001): Myxidium leei (Myxozoa) infections in aquarium-reared Mediterranean fish species. Dis. Aquat. Org., 47, 57-62.

Palenzuela, O., M. J. Redondo and P. Álvarez-Pellitero (2002): Description of Enteromyxum scophthalmi gen. nov., sp. nov. (Myxozoa), an intestinal parasite of turbot (Scophthalmus maximus L.) using morphological and ribosomal RNA sequence data. Parasitology, 124, 369-379.

Redondo, M. J., O. Palenzuela, A. Riaza, A. Macias and P. Álvarez-Pellitero (2002): Experimental transmission of Enteromyxum scophthalmi (Myxozoa), an enteric parasite of turbot Scophthalmus maximus. J. Parasitol., 88, 482488.

Sakiti, N., V. Tarer, D. Jacquemin and A. Marques (1996): Presence en Mediterranee occidentale d'une Mixosporidie histozoique pathogene dans les elevages du daurade, Sparus aurata. Ann. Sci. Nat. Zool., Paris, 17, 123-127.

Schlegel, M., J. Lom, A. Stechmann, D. Bernhard, D. Leipe, I. Dyková and M. L. Sogin (1996): Phylogenetic analysis of complete small subunit ribosomal RNA coding region of Myxidium lieberkuehni: evidence that Myxozoa are Metazoa and related to the bilateria. Arch. Protistenkd., 147, 
$1-9$

Swofford, D. L. (1999): PAUP - phylogenetic analysis using parsimony, version 4.0. Sinauer associates, Inc Publishers, Sunderland, MA.

Thompson, J. D., T. J. Gibson, F. Plewniak, F. Jeanmougin and D. G. Higgins (1997): The CLUSTAL_X windows interface: flexible strategies for multiple sequence alignment aided by quality analysis tools. Nucleic Acids Res., 25, 48764882.

Tin Tun, H. Yokoyama, K. Ogawa and H. Wakabayashi (2000): Myxosporeans and their hyperparasitic microsporeans in the intestine of emaciated tiger puffer. Fish Pathol., 35, $145-156$

Tin Tun, K. Ogawa and H. Wakabayashi (2002): Pathological changes induced by three myxosporeans in the intestine of cultured tiger puffer, Takifugu rubripes (Temminck and Schlegel). J. Fish Dis., 25, 63-72.

Wakabayashi, H. (1996): Importation of aquaculture seedlings to Japan. Rev. Sci. Tech., 15, 409-422.
Yasuda, H., T. Ooyama, K. Iwata, Tin Tun, H. Yokoyama and K. Ogawa (2002): Fish-to-fish transmission of Myxidium spp. (Myxozoa) in cultured tiger puffer suffering from emaciation disease. Fish Pathol., 37, 29-33.

Yokoyama, H., J.-H. Kim, J. Sato, M. Sano and K. Hirano (1996): Fluorochrome Uvitex 2B stain for detection of the microsporidian causing beko disease of yellowtail and goldstriped amberjack juveniles. Fish Pathol., 31, 99104.

Yokoyama, H., M. A. Freeman, T. Yoshinaga and K. Ogawa (2004a): Myxobolus buri, the myxosporean parasite causing scoliosis of yellowtail, is synonymous with Myxobolus acanthogobii infecting the brain of the yellowfin goby. Fish. Sci. (in press).

Yokoyama, H., C. M. Whipps, M. L. Kent, K. Mizuno and H. Kawakami (2004b): Kudoa thyrsites from Japanese flounder and Kudoa lateolabracis n. sp. from Chinese sea bass: causative myxozoans of post-mortem myoliquefaction. Fish Pathol., 39, 79-85. 